\title{
Etiology of Diarrhea among Severely Malnourished Infants and Young Children: Observation of Urban-Rural Differences over One Decade in Bangladesh ${ }^{*}$
}

\author{
Sumon Kumar Das, Mohammod Jobayer Chisti, Sayeeda Huq, Mohammad Abdul Malek, \\ Mohammed Abdus Salam, Tahmeed Ahmed, Abu Syed Golam Faruque ${ }^{\#}$ \\ International Centre for Diarrheal Disease Research, Dhaka, Bangladesh. \\ Email: sumon@icddrb.org, chisti@icddrb.org, sayeeda@icddrb.org, mamalek@icddrb.org, masalam@icddrb.org,

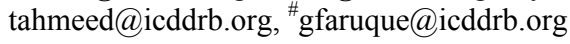

Received December $12^{\text {th }}, 2012$; revised January $12^{\text {th }}, 2013$; accepted January $20^{\text {th }}, 2013$

\begin{abstract}
There is inadequate information on the etiology of diarrhea in severely malnourished (SM) young children. Thus, the study aimed to determine the etiology of diarrhea among severely malnourished (z score $<-3.00$ SD) children in rural and urban Bangladesh. From the database (2000-2011) of Diarrheal Disease Surveillance Systems (DDSS) at rural Matlab and urban Dhaka hospitals of icddr,b, 2234 and 3109 under-5 children were found severely malnourished (underweight, stunted or wasted) respectively. Two comparison groups [moderately malnourished (MM) and well-nourished (WN)] were randomly selected in a ratio of 1:1:1. Children with all categories of SM were more likely to be infected with Vibrio cholerae (rural-11\%; urban-15\%), Shigella (16\%; 9\%), Salmonella (1\%; 2\%) and Campylobacter $(3 \% ; 4 \%)$; and less likely to have rotavirus $(25 \% ; 20 \%)$ compared to only one SM category. Isolation rate of Vibrio cholerae was significantly higher among SM both in rural and urban children $(7 \% ; 13 \%)$ than those of MM $(5 \% ; 10 \%)$ and WN $(2 \% ; 8 \%)$ and lower for rotavirus $(30 \% ; 31 \%),(34 \% ; 43 \%),(35 \% ; 47 \%)$ respectively $(\mathrm{p}<0.01)$. However, for Shigella it was only higher among rural SM children $(11 \%)$ [MM $(9 \%)$, and $\mathrm{WN}(8 \%)(\mathrm{p}<0.01)]$. The isolation rate of Salmonella in SM $(2 \%)$ was similar to that in MM $(2 \% ; \mathrm{p}=0.72)$ but significantly higher than that in WN $(1 \%$; $<<$ 0.01 ) among urban children. Isolation rates of bacterial enteric pathogens were higher but rotavirus was lower in SM children in both rural and urban area with geographical heterogeneity.
\end{abstract}

Keywords: Diarrhea; Under-5 Children; Rural; Severe Malnutrition; Urban

\section{Introduction}

Despite reductions in global deaths due to diarrhea in under five children to around 400,000 each year, globally (range, 200,000 to 500,000) during 2000-2010, the mortality rate is still high [1] and diarrhea remains the second leading cause of childhood deaths [2]. Malnutrition is associated with both macro-and micronutrient deficiencies [3], and directly or indirectly related to $35 \%$ of all deaths among under-five children [4]. Severe malnutrition is often associated with life-threatening consequences such as hypoglycaemia, hypothermia, hypernatremia, severe chest infection, sepsis, and severe electrolyte disturbances [5].

Childhood malnutrition remains an important public

\footnotetext{
"There is no potent conflict of interest to declare. All authors confirm that there is no professional affiliation, financial agreement or other involvement with any company whose product figures prominently in the submitted manuscript.

${ }^{\#}$ Corresponding author.
}

health problem in Asian subcontinent; although most of the countries in this region have experienced rapid economic development in the recent years [3]. Each of the different types of nutritional deficits such as underweight, stunting and wasting is associated with increased deaths from diarrhea, respiratory infections and other infectious diseases such as measles [6]. A 4-year prospective study among severely acute malnourished children aged 6 months to 12 years, hospitalized with diarrhea experienced higher deaths compared to the children who did not have diarrhea during their hospital stay [7]. A cohort study of 430 Zambian children aged 6 - 59 months with severe acute malnutrition noted 2.5 times higher deaths in those with diarrhea on admission compared to those who did not have diarrhea [8].

According to Bangladesh Demographic and Health Survey 2011, the prevalence of childhood stunting, underweight and wasting were $43 \%, 41 \%$ and $17 \%$ respectively [9]. Most of the earlier studies have identified as- 
sociation between malnutrition and diarrhea and examined association of etiologic agents of diarrhea with malnutrition [10-12]. However, most of the analyses did not consider geographical diversity. In our analysis, we examined the distribution of the common etiology of diarrhea among severely malnourished under-five children in two distinct geographical locations.

\section{Materials and Methods}

\subsection{Study Site}

The study was conducted among the under-five children visiting the urban Dhaka Hospital and rural Matlab Hospital of the International Centre for Diarrheal Disease Research, Bangladesh (icddr,b).

\subsubsection{Dhaka Hospital}

Established in 1963, the Dhaka Hospital, located in urban Dhaka, currently provides cost free care and treatment to around 140,000 diarrheal patients each year. The hospital maintains a Diarrheal Disease Surveillance System (DDSS) since 1979 , and systematically enrolls (2\% since 1996) patients attending the facility, irrespective of age and sex. The DDSS provides valuable information to hospital clinicians in their decision-making processes and enables to detect the emergence of new pathogens and in early identification of outbreaks and their locations, thereby alerts the host government to take appropriate preventive and control measures. Extensive microbiological assessments of fecal samples (culture, ELISA, and microscopy) are performed to identify diarrheal pathogens.

\subsubsection{Matlab Hospital}

icddr,b maintains a treatment facility in rural Matlab (Matlab Hospital), about 55 kilometres from Dhaka, since 1963. It provides free treatment to $12,000-15,000$ diarrhea patients annually reporting from Health and Demographic Surveillance System area and other adjoining sub-districts. The Matlab DDSS has been initiated in 2000, which enrolls all patients coming from the areas of active Health and Demographic Surveillance System (HDSS) of icddr,b.

\subsection{Definition}

Diarrhea was defined as passage of three or more abnormally loose or watery stool within last 24 hours. Severe malnutrition was defined (using z-scores) as: severe stunting (SS; height-for-age $\mathrm{z}$-score $<-3.00$ ); severe underweight (SU; weight-for-age z-score $<-3.00$ ), and severe wasting (SW; weight-for-height z-score $<-3.00$ ), using the World Health Organization reference value [12]. Moderate malnutrition was defined as follows: moderate stunting (height-for-age $z$-score -3.00 to $<-2.00$ ); mod- erate underweight (weight-for-age z-score -3.00 to $<$ -2.00 ); and moderate wasting (weight-for-height z-score -3.00 to $<-2.00$ ). We considered children as well-nourished if their z-scores for weight-for-age, height-for-age and weight-for-height $\mathrm{z}$-score were form -2.00 to +1.00 .

\subsection{Sample Frame}

From 2000 to 2011, at the rural Matlab Hospital 10,794 under-five children were enrolled in DDSS; and 27,276 under-five children at the urban Dhaka Hospital. Out of all under-5 children, 2234 children in Matlab and 3109 children in Dhaka were severely malnourished defined by any of the above mentioned categories: SU (364 and 518 respectively); SS (449 and 502 respectively); SW (253 and 242 respectively); SU with SS (530 and 929 respectively); SU with SW (456 and 563 respectively); and SU with SS with SW (182 and 355 respectively); but none of them had both SS and SW. For each severely malnourished child, we randomly selected one child with moderate malnutrition and one well-nourished child for comparison from both rural and urban hospitals.

\subsection{Data Analysis}

Data analyses were done using Statistical Package for Social Sciences (SPSS) Windows (Version 15.2; Chicago, IL) and Epi Info (Version 6.0, USD, Stone Mountain, GA). Descriptive analysis was employed and Chi-square test was performed for comparing proportions and a probability of $<0.05$ was considered as statistically significant. Strength of association was determined by estimating odds ratio (OR) and its $95 \%$ confidence interval (CI).

\subsection{Ethical Consideration}

The DDSS of icddr,b is a regular disease monitoring system of the hospitals, which had approval of the Research Review Committee (RRC) and Ethical Review Committee (ERC) of icddr,b.

\section{Results}

Children under 5 years, who were severely underweight, wasted and stunted, were more likely to be infected with Vibrio cholerae, Shigella, Salmonella and Campylobacter; and less likely to be infected with rotavirus in rural Matlab (Table 1). Analogous observation was also found only for rotavirus in the urban Dhaka; however, distribution of other pathogens was found almost similar (Table 2).

The isolation rates of Shigella were higher in rural area. However, Vibrio cholerae and Campylobacter were higher among urban severely malnourished children compared 
to their rural counterparts (Table 3).

Severely malnourished children from rural Matlab were more likely to be infected with Vibrio cholerae than well-nourished and moderately malnourished children. So for Shigella; Shigella flexneri and Shigella dysenteriae were more prevalent among severely malnourished children compared to well-nourished. Conversely, children with severe malnutrition less likely experienced rotaviral diarrhea compared to well-nourished children, and the proportion was even lower than moderately malnourished children (Table 4).

On the other hand, in urban Dhaka, similar trend of isolation pattern for Vibrio cholerae and rotavirus was observed among under-5 children with severe malnutrition compared to moderately malnourished and wellnourished. Although, isolation rate of Salmonella was very low among all the groups, it was higher among severely malnourished children than others (Table 5). The isolation rates of Campylobacter, Entamoeba histolytica, and Giardia lamblia were found to be identical in all the groups (Tables 4 and 5).

\section{Discussion}

Significant variations in isolation pattern of common enteropathogens causing diarrhea among severely malnourished under-5 years old children in both rural and urban areas were observed. However, isolation rates were also significantly different between urban and rural area.

Vibrio cholerae, Shigella and rotavirus are the major pathogens that cause diarrhea [13]. Children under 5 years of age have the highest burden of cholera in the endemic areas $[14,15]$, and also at risk to have dehydrateing diarrhea $[16,17]$. Study suggested a lack of innate and cell-mediated immune responses among children against $V$. cholerae [18]. Conversely, malnutrition is a risk factor for shigellosis and children infected with Shigella were also likely to become malnourished [19]. Malnutrition

Table 1. Distribution of pathogens by nutritional status category of the under-five children at rural Matlab Hospital (2000-2011).

\begin{tabular}{|c|c|c|c|c|c|c|}
\hline Pathogens & $\begin{array}{c}\text { SU } \\
n=364(\%)\end{array}$ & $\begin{array}{c}\text { SS } \\
n=449(\%)\end{array}$ & $\begin{aligned} & S W \\
n= & 253(\%)\end{aligned}$ & $\begin{array}{l}\text { SU with SS } \\
n=530(\%)\end{array}$ & $\begin{array}{l}\text { SU with SW } \\
n=456(\%)\end{array}$ & $\begin{array}{c}\text { SU with SS with SW } \\
n=182(\%)\end{array}$ \\
\hline Vibrio cholerae & $23(6)^{*}$ & $20(5)^{*}$ & $5(2)^{*}$ & $47(9)$ & $39(9)$ & $20(11)$ \\
\hline Overall Shigella & $34(9)^{*}$ & $51(11)$ & $25(10)^{*}$ & $63(12)$ & $48(11)$ & $29(16)$ \\
\hline S. flexneri & $26(7)$ & $37(8)$ & $18(7)$ & $46(9)$ & $38(8)$ & $20(11)$ \\
\hline S. sonnei & $1(0)$ & $2(0)$ & $4(2)$ & $8(2)$ & $3(1)$ & $2(1)$ \\
\hline S. dysenteriae & $5(1)$ & $5(1)$ & $2(1)$ & $4(1)$ & $1(0)$ & $4(2)$ \\
\hline S. boydii & $2(1)$ & $7(2)$ & $1(0)$ & $5(1)$ & $6(1)$ & $3(2)$ \\
\hline Salmonella & $7(2)$ & $4(1)$ & $4(2)$ & $7(1)$ & $8(2)$ & $1(1)$ \\
\hline Rotavirus & $108(30)$ & $144(32)$ & $95(38)^{*}$ & $135(26)$ & $141(31)$ & $46(25)$ \\
\hline Campylobacter & $7(2)$ & $5(1)$ & $8(3)$ & $14(3)$ & $12(3)$ & $5(3)$ \\
\hline E. histolytica & $1(0)$ & $3(1)$ & $1(0)$ & $9(2)$ & $1(0)$ & 0 \\
\hline Giardia lamblia & $9(3)$ & $3(1)$ & $2(1)$ & $14(3)$ & $5(1)$ & $2(1)$ \\
\hline
\end{tabular}

SU, severe underweight; SS, severe stunting; SW, severe wasting. ${ }^{*}$ Values were compared with SU with SS with SW and were significant at $5 \%$ level.

Table 2. Distribution of pathogens by nutritional status category of the under-five children at urban Dhaka Hospital (2000-2011).

\begin{tabular}{|c|c|c|c|c|c|c|}
\hline Pathogens & $\begin{array}{c}\mathrm{SU} \\
\mathrm{n}=518(\%)\end{array}$ & $\begin{array}{c}\text { SS } \\
n=502(\%)\end{array}$ & $\begin{array}{c}\text { SW } \\
n=242(\%)\end{array}$ & $\begin{array}{l}\text { SU with SS } \\
n=929(\%)\end{array}$ & $\begin{array}{l}\text { SU with SW } \\
n=563(\%)\end{array}$ & $\begin{array}{l}\text { SU with SS with SW } \\
n=355(\%)\end{array}$ \\
\hline Vibrio cholerae & $63(12)$ & $61(12)$ & 39 (16) & $124(13)$ & $62(11)$ & $54(15)$ \\
\hline S. flexneri & $15(3)$ & $16(3)$ & $2(1)$ & $31(3)$ & $15(3)$ & $21(6)$ \\
\hline S. sonnei & $2(0)$ & $2(0)$ & $0(0)$ & $7(1)$ & $8(1)$ & $3(1)$ \\
\hline S. boydii & $4(1)$ & $6(1)$ & $5(2)$ & $14(2)$ & $2(0)$ & $5(1)$ \\
\hline Salmonella & $7(1)$ & $9(2)$ & $5(2)$ & $13(1)$ & $15(3)$ & $7(2)$ \\
\hline Rotavirus & $176(35)^{*}$ & $208(42)^{*}$ & $84(35)^{*}$ & $231(25)^{*}$ & $177(32)^{*}$ & $68(20)$ \\
\hline Campylobacter & $22(4)$ & $17(3)$ & $12(5)$ & $35(4)$ & $22(4)$ & $14(4)$ \\
\hline E. histolytica & $0(0)$ & $3(1)$ & $0(0)$ & $2(0)$ & $6(1)$ & $1(0)$ \\
\hline
\end{tabular}

SU, severe underweight; SS, severe stunting; SW, severe wasting. ${ }^{*}$ Values were compared with SU with SS with SW and were significant at $5 \%$ level. 
Table 3. Urban-rural differentiation of pathogens among severely malnourished under-5 children (2000-2011).

\begin{tabular}{|c|c|c|c|}
\hline Pathogens & Rural; n = $2234(\%)$ & Urban; n = 3109 (\%) & OR $(95 \%$ CI) p value \\
\hline Vibrio cholerae & $154(7)$ & $403(13)$ & $0.50(0.40,0.61)<0.001$ \\
\hline Overall Shigella & $250(11)$ & $178(6)$ & $2.07(1.69,2.55)<0.001$ \\
\hline S. flexneri & $185(8)$ & $100(3)$ & $2.72(2.10,3.51)<0.001$ \\
\hline S. sonnei & $20(1)$ & $22(1)$ & $1.27(0.66,2.42) 0.542$ \\
\hline S. dysenteriae & $21(1)$ & $20(6)$ & $1.47(0.76,2.82) 0.285$ \\
\hline S. boydii & $24(1)$ & $36(1)$ & $0.93(0.53,1.60) 0.877$ \\
\hline Salmonella & $31(1)$ & $56(2)$ & $0.77(0.48,1.22) 0.285$ \\
\hline Rotavirus & $669(30)$ & $944(31)$ & $0.98(0.87,1.11) 0.766$ \\
\hline Campylobacter & $51(2)$ & $122(4)$ & $0.57(0.41,0.81) 0.001$ \\
\hline E. histolytica & $15(1)$ & $12(0)$ & $1.74(0.77,3.97) 0.209$ \\
\hline Giardia lamblia & $35(1)$ & $16(1)$ & $3.08(1.64,5.82)<0.001$ \\
\hline
\end{tabular}

Table 4. Distribution of pathogens among severely malnourished, moderately malnourished and well nourished under-5 children in rural Matlab Hospital (2000-2011).

\begin{tabular}{cccccc}
\hline Pathogens & $\begin{array}{c}\text { Severely malnourished } \\
\mathbf{n}=\mathbf{2 2 3 4}(\mathbf{\%})\end{array}$ & $\begin{array}{c}\text { Moderately malnourished } \\
\mathbf{n}=\mathbf{2 2 3 4}(\mathbf{\%})\end{array}$ & OR (95\% CI) $\mathbf{p}$ value & $\begin{array}{c}\text { Well nourished } \\
\mathbf{n}=\mathbf{2 2 3 4} \mathbf{( \% )}\end{array}$ & OR (95\% CI) $\mathbf{p}$ value $^{\mathbf{b}}$ \\
\hline Vibrio cholerae & $154(7)$ & $107(5)$ & $1.47(1.13,1.91) 0.003$ & $41(2)$ & $3.969(2.76,5.71)<0.001$ \\
Overall Shigella & $250(11)$ & $202(9)$ & $1.27(1.04,1.55) 0.019$ & $176(8)$ & $1.47(1.20,1.81)<0.001$ \\
S. flexneri & $185(8)$ & $157(7)$ & $1.19(0.95,1.50) 1.28$ & $136(6)$ & $1.39(1.10,1.76) 0.005$ \\
S. sonnei & $20(1)$ & $20(1)$ & $1.00(0.51,1.94) 0.873$ & $13(1)$ & $1.54(0.73,3.29) 0.294$ \\
S. dysenteriae & $21(1)$ & $12(1)$ & $1.76(0.82,3.80) 0.162$ & $6(0)$ & $3.52(1.35,9.75) 0.006$ \\
S. boydii & $24(1)$ & $13(1)$ & $1.86(0.90,3.86) 0.098$ & $21(1)$ & $1.14(0.61,2.14) 0.764$ \\
Salmonella & $31(1)$ & $29(1)$ & $1.07(0.62,1.83) 0.896$ & $31(1)$ & $1.00(0.59,1.70) 0.898$ \\
Rotavirus & $669(30)$ & $755(34)$ & $0.84(0.74,0.95) 0.006$ & $771(35)$ & $0.81(0.71,0.92) 0.001$ \\
Campylobacter & $51(2)$ & $44(2)$ & $1.16(0.76,1.78) 0.533$ & $38(2)$ & $1.35(0.87,2.11) 0.198$ \\
E. histolytica & $15(1)$ & $11(1)$ & $1.37(0.59,3.19) 0.555$ & $4(0)$ & $3.77(1.17,13.43) 0.021$ \\
Giardia lamblia & $35(2)$ & $36(2)$ & $0.97(0.59,1.59) 1.000$ & $35(2)$ & $1.00(0.61,1.64) 0.904$ \\
\hline
\end{tabular}

${ }^{a}$ Comparison between severely malnourished vs. moderately malnourished; ${ }^{b}$ Comparison between severely malnourished vs. well-nourished.

Table 5. Distribution of pathogens among severely malnourished, moderately malnourished and well nourished under-five children at the urban Dhaka Hospital (2000-2011).

\begin{tabular}{|c|c|c|c|c|c|}
\hline Pathogens & $\begin{array}{l}\text { Severely malnourished } \\
\mathrm{n}=3109(\%)\end{array}$ & $\begin{array}{l}\text { Moderately malnourished } \\
n=3109(\%)\end{array}$ & OR (95\% CI) p value ${ }^{\mathrm{a}}$ & $\begin{array}{l}\text { Well nourished } \\
\mathrm{n}=3109(\%)\end{array}$ & OR $(95 \%$ CI $)$ p value ${ }^{b}$ \\
\hline Vibrio cholerae & $403(13)$ & $317(10)$ & $1.31(1.12,1.54)<0.001$ & $248(8)$ & $1.72(1.45,2.04)<0.001$ \\
\hline Overall Shigella & $178(6)$ & $151(5)$ & $1.19(0.95,1.50) 0.140$ & $160(5)$ & $1.12(0.89,1.40) 0.341$ \\
\hline S. flexneri & $100(3)$ & $82(3)$ & $1.23(0.90,1.67) 0.200$ & $82(3)$ & $1.23(0.90,1.67) 0.200$ \\
\hline S. sonnei & $22(1)$ & $23(1)$ & $0.96(0.51,1.78) 1.000$ & $29(1)$ & $0.76(0.42,1.36) 0.398$ \\
\hline S. dysenteriae & $20(6)$ & $9(0)$ & $1.06(0.54,2.07) 0.991$ & $9(0)$ & $2.23(0.96,5.29) 0.062$ \\
\hline S. boydii & $36(1)$ & $37(1)$ & $0.97(0.60,1.58) 1.000$ & $40(1)$ & $0.90(0.56,1.45) 0.729$ \\
\hline Salmonella & $56(2)$ & $38(1)$ & $1.48(0.96,2.29) 0.077$ & $30(1)$ & $1.88(1.18,3.01) 0.006$ \\
\hline Rotavirus & $944(31)$ & $1328(43)$ & $0.58(0.53,0.65)<0.001$ & $1445(47)$ & $0.50(0.45,0.56)<0.001$ \\
\hline Campylobacter & $122(4)$ & $143(5)$ & $0.85(0.66,1.09) 0.209$ & $124(4)$ & $0.98(0.76,1.28) 0.948$ \\
\hline E. histolytica & $12(<1)$ & $5(<1)$ & $2.41(0.79,7.82) 0.145$ & $3(<1)$ & $4.01(1.06,17.88) 0.038$ \\
\hline Giardia lamblia & $16(1)$ & $25(1)$ & $0.64(0.32,1.24) 0.210$ & $21(1)$ & $0.76(0.38,1.52) 0.509$ \\
\hline
\end{tabular}

${ }^{\mathrm{a}}$ Comparison between severely malnourished vs. moderately malnourished; ${ }^{\mathrm{b}}$ Comparison between severely malnourished vs. well-nourished. 
causes atrophy and decreased cell proliferation of the Thymus gland resulting in depletion of CD4+ CD8+ thymocytes $[20,21]$. Thus, there is impaired peripheral immune response that favors the pathogens to become virulent. This might explain the higher rate of isolation of $V$. cholerae and Shigella among severely malnourished children compared to others. Moreover, severe malnutrition leads to atrophy of the gastric mucosa resulting in less production of hydrochloric acid which favors the higher rate of infection due to less infective doses of common bacterial pathogens [22]. On the other hand, rotavirus causes diarrhea either by malabsorption seconddary to enterocyte destruction, a virus-encoded toxin, stimulation of the enteric nervous system (ENS), and villus ischemia $[23,24]$ in malnutrition. Malnutrition causes decreased number of intestinal lining epithelial cells and impair its proliferation [25]. Thus, due to lack of mucosal cells to adhere for rotavirus causing diarrhea would be the possible explanation of lower isolation rate among severely malnourished children.

Distinct geographical variation may explain the diversity in socio-demographic and cultural factors, watersanitation practices and also mass rotavirus vaccination in rural Matlab [26] might explain the diverse isolation rates between rural-urban areas in addition to household food security. Recent mass rotaviral vaccination might trigger the other pathogens to become virulent or survive better in environment.

Severe malnutrition is a complex phenomenon, involving interactions of the biological, cultural and socioeconomic factors [27]. Parental education, lower socioeconomic status, and poor nutritional characteristics, childfeeding practices, and birth-order have strong association with severe malnutrition [10,27]. Conversely, association with higher family food insecurity, low quality of complementary foods and high burdens of intestinal parasitic loads and other infections which are persisting despite improvements in socio-economic conditions over recent years have also been documented [28,29]. Severely malnourished children are always vulnerable to any infections including diarrhea due to compromised immune function [30]. Having all the category of severe malnutrition, a child would be highly susceptible to serious infections. Severe malnutrition with the co-morbidity of diarrhea $[31,32]$ is a life threatening condition with high fatality rate (20\%) [7]; however, the present observation was not aimed to determine the fatal outcome. Other than that, contaminated weaning foods prepared under unhygienic conditions is a major risk factor for causing diarrheal diseases and associated malnutrition [33]. A standardized protocol for management of severe malnutrition with diarrhea among under 5 years old children was introduced in the Dhaka hospital of icddr,b that reduced mortality by at least $47 \%[34,35]$; moreover, early detection of entero-pathogens helps the clinicians for rational use of antimicrobials and appropriate management of these high risk severely malnourished children.

\section{Limitations}

Although unbiased systematic sampling method was used to enroll patients into surveillance system irrespective of age, sex, nutritional status, disease severity or socioeconomic background and the large dataset with standard laboratory facility were supportive of the strengths of this analysis; however, hospital data might not be representative of the general population.

\section{Conclusion}

Severely malnourished children were more prone to be infected with common bacterial pathogens compared to those without severe malnutrition. Integrated management with early and appropriate antimicrobial therapy needs to be introduced in addition to other resuscitative measures. Furthermore, round the clock monitoring needs to be continued to observe any changing pattern of isolation rates of the common pathogens and also there are needs to determine the frequency of isolation of other pathogens causing diarrhea and fatal outcomes.

\section{Acknowledgements}

Hospital surveillance was funded by icddr,b and the Government of the People's Republic of Bangladesh through IHP-HNPRP. icddr,b acknowledges with gratitude the commitment of the Government of the People's Republic of Bangladesh to the Centre's research efforts. icddr,b also gratefully acknowledges the following donors which provide unrestricted support to the Centre's research efforts: Australian Agency for International Development (AusAID), Government of the People's Republic of Bangladesh, Canadian International Development Agency (CIDA), Embassy of the Kingdom of the Netherlands (EKN), Swedish International Development Cooperation Agency (Sida), Swiss Agency for Development and Cooperation (SDC), and Department for International Development, UK (DFID).

\section{REFERENCES}

[1] L. Liu, H. L. Johnson, S. Cousens, J. Perin, S. Scott, J. E. Lawn, I. Rudan, H. Campbell, R. Cibulskis, M. Li, C. Mathers and R. E. Black, "Global, Regional, and National Causes of Child Mortality: An Updated Systematic Analysis for 2010 with Time Trends since 2000," Lancet, Vol. 379, No. 9832, 2012, pp. 2151-2161. doi:10.1016/S0140-6736(12)60560-1 
[2] F. Alkizim, D. Matheka and A. Muriithi, "Childhood Diarrhoea: Failing Conventional Measures, What Next?" Pan African Medical Journal, Vol. 8, No. 51, 2011, p. 47. doi:10.4314/pamj.v8i1.71164

[3] S. R. Pasricha and B. A. Biggs, "Undernutrition among Children in South and South-East Asia," Journal of Paediatrics and Child Health, Vol. 46, No. 9, 2010, pp. 497-503. doi:10.1111/j.1440-1754.2010.01839.x

[4] World Health Organization (WHO), "Severe Acute Malnutrition," WHO, Geneva, 2004.

[5] World Health Organization (WHO), "Maternal, Newborn, Child and Adolescent Health: Serious Childhood Problems in Countries with Limited Resources," WHO, Geneva, 2004.

[6] R. E. Black, L. H. Allen, Z. A. Bhutta, L. E. Caulfield, M. de Onis, M. Ezzati, C. Mathers and J. Rivera, "Maternal and Child Undernutrition: Global and Regional Exposures and Health Consequences," Lancet, Vol. 371, No. 9608, 2008, pp. 243-260. doi:10.1016/S0140-6736(07)61690-0

[7] A. Talbert, N. Thuo, J. Karisa, C. Chesaro, E. Ohuma, J. Ignas, J. A. Berkley, C. Toromo, S. Atkinson and K. Maitland, "Diarrhoea Complicating Severe Acute Malnutrition in Kenyan Children: A Prospective Descriptive Study of Risk Factors and Outcome," PLoS One, Vol. 7, No. 6, 2012, p. e38321. doi:10.1371/journal.pone.0038321

[8] A. H. Irena, M. Mwambazi and V. Mulenga, "Diarrhea is a Major Killer of Children with Severe Acute Malnutrition Admitted to Inpatient Set-Up in Lusaka, Zambia," Nutrition Journal, Vol. 10, 2011, p. 110. doi:10.1186/1475-2891-10-110

[9] "Bangladesh Demographic and Health Survey," 2011. www.measuredhs.com/pubs/pdf/PR15/PR15.pdf

[10] M. J. Chisti, M. I. Hossain, M. A. Malek, A. S. Faruque, T. Ahmed and M. A. Salam, "Characteristics of Severely Malnourished Under-Five Children Hospitalized with Diarrhoea, and Their Policy Implications," Acta Paediatrica, Vol. 96, No. 5, 2007, pp. 693-696. doi:10.1111/j.1651-2227.2007.00192.x

[11] B. Nahar, M. I. Hossain, J. D. Hamadani, T. Ahmed, S. N. Huda, S. M. Grantham-McGregor and L. A. Persson, "Effects of a Community-Based Approach of Food and Psychosocial Stimulation on Growth and Development of Severely Malnourished Children in Bangladesh: A Randomised Trial," European Journal of Clinical Nutrition, Vol. 66, No. 6, pp. 701-709. doi:10.1038/ejcn.2012.13

[12] B. Nahar, T. Ahmed, K. H. Brown and M. I. Hossain, "Risk Factors Associated with Severe Underweight among Young Children Reporting to a Diarrhoea Treatment Facility in Bangladesh," Journal of Health, Population, and Nutrition, Vol. 28, No. 5, pp. 476-483.

[13] D. M. Denno, N. Shaikh, J. R. Stapp, X. Qin, C. M. Hutter, V. Hoffman, J. C. Mooney, K. M. Wood, H. J. Stevens, R. Jones, P. I. Tarr and E. J. Klein, "Diarrhea Etiology in a Pediatric Emergency Department: A Case Control Study," Clinical Infectious Diseases, Vol. 55, No. 7, 2012, pp. 897-904. doi:10.1093/cid/cis553

[14] J. L. Deen, L. von Seidlein, D. Sur, M. Agtini, M. E.
Lucas, A. L. Lopez, D. R. Kim, M. Ali and J. D. Clemens, "The High Burden of Cholera in Children: Comparison of Incidence from Endemic Areas in Asia and Africa," PLoS Neglected Tropical Diseases, Vol. 2, No. 2, 2008, p. e173. doi:10.1371/journal.pntd.0000173

[15] R. B. Sack, A. K. Siddique, I. M. Longini, Jr., A. Nizam, M. Yunus, M. S. Islam, J. G. Morris, Jr., A. Ali, A. Huq, G. B. Nair, F. Qadri, S. M. Faruque, D. A. Sack and R. R. Colwell, "A 4-Year Study of the Epidemiology of Vibrio Cholerae in Four Rural Areas of Bangladesh," The Journal of Infectious Diseases, Vol. 187, No. 1, 2003, pp. 96-101. doi:10.1086/345865

[16] D. Legros, M. McCormick, C. Mugero, M. Skinnider, D. D. Bek'Obita and S. I. Okware, "Epidemiology of Cholera Outbreak in Kampala, Uganda," East African Medical Journal, Vol. 77, No. 7, 2000, pp. 347-349.

[17] M. A. Luque Fernandez, P. R. Mason, H. Gray, A. Bauernfeind, J. F. Fesselet and P. Maes, "Descriptive Spatial Analysis of the Cholera Epidemic 2008-2009 in Harare, Zimbabwe: A Secondary Data Analysis," Transactions of the Royal Society of Tropical Medicine and Hygiene, Vol. 105, No. 1, 2011, pp. 38-45. doi:10.1016/j.trstmh.2010.10.001

[18] D. T. Leung, F. Chowdhury, S. B. Calderwood, F. Qadri and E. T. Ryan, "Immune Responses to Cholera in Children," Expert Review of Anti-Infective Therapy, Vol 10, No. 4, 2012, pp. 435-444. doi:10.1586/eri.12.23

[19] R. N. Mazumder, H. Ashraf, S. S. Hoque, I. Kabir, N. Majid, M. A. Wahed, G. J. Fuchs and D. Mahalanabis, "Effect of an Energy-Dense Diet on the Clinical Course of Acute Shigellosis in Undernourished Children," The British Journal of Nutrition, Vol. 84, No. 5, 2000, pp. 775-779.

[20] W. Savino, "The Thymus Gland Is a Target in Malnutrition," European Journal of Clinical Nutrition, Vol. 56, Suppl. 3, 2002, pp. S46-S49. doi:10.1038/sj.ejen.1601485

[21] W. Savino and M. Dardenne, "Nutritional Imbalances and Infections Affect the Thymus: Consequences on T-CellMediated Immune Responses," Proceedings of the $\mathrm{Nu}$ trition Society, Vol. 69, No. 4, 2010, pp. 636-643. doi:10.1017/S0029665110002545

[22] R. H. Gilman, R. Partanen, K. H. Brown, W. M. Spira, S. Khanam, B. Greenberg, S. R. Bloom and A. Ali, "Decreased Gastric Acid Secretion and Bacterial Colonization of the Stomach in Severely Malnourished Bangladeshi Children," Gastroenterology, Vol. 94, No. 6, 1988, pp. 1308-1314.

[23] M. E. Conner and R. F. Ramig, "Viral Enteric Diseases," Lippincott-Raven Publishers, Philadelphia, 1997.

[24] O. Lundgren and L. Svensson, "The Enteric Nervous System and Infectious Diarrhea," Elsevier Science BV, Amsterdam, 2003.

[25] E. Guiraldes and J. R. Hamilton, "Effect of Chronic Malnutrition on Intestinal Structure, Epithelial Renewal, and Enzymes in Suckling Rats," Pediatric Research, Vol. 15, No. 6, 1981, pp. 930-934. doi:10.1203/00006450-198106000-00010 
[26] K. Zaman, M. Yunus, S. El Arifeen, T. Azim, A. S. Faruque, E. Huq, I. Hossain, S. P. Luby, J. C. Victor, M. J. Dallas, K. D. Lewis, S. B. Rivers, A. D. Steele, K. M. Neuzil, M. Ciarlet and D. A. Sack, "Methodology and Lessons-Learned from the Efficacy Clinical Trial of the Pentavalent Rotavirus Vaccine in Bangladesh," Vaccine, Vol. 30, Suppl. 1, 2012, pp. A94-A100. doi:10.1016/j.vaccine.2011.07.117

[27] B. Nahar, T. Ahmed, K. H. Brown and M. I. Hossain, "Risk Factors Associated with Severe Underweight among Young Children Reporting to a Diarrhoea Treatment Facility in Bangladesh," Joyrnal of Health, Population, and Nutrition, Vol. 28, No. 5, 2010, pp. 476-483.

[28] B. S. Schwartz, J. B. Harris, A. I. Khan, R. C. Larocque, D. A. Sack, M. A. Malek, A. S. Faruque, F. Qadri, S. B. Calderwood, S. P. Luby and E. T. Ryan, "Diarrheal Epidemics in Dhaka, Bangladesh, during Three Consecutive Floods: 1988, 1998, and 2004," The American Journal of Tropical Medicine and Hygiene, Vol. 74, No. 6, 2006, pp. 1067-1073.

[29] P. Sanchez, M. S. Swaminathan, P. Dobie and N. Yuksel, "Un Millennium Project 2005. Halving Hunger: It Can Be Donetask Force on Hunger," Earthscan, London and Sterling, 2005.

[30] J. Picot, D. Hartwell, P. Harris, D. Mendes, A. J. Clegg and A. Takeda, "The Effectiveness of Interventions to Treat Severe Acute Malnutrition in Young Children: A Systematic Review," Health Technology Assessment, Vol. 16, No. 19, 2012, pp. 1-316. doi:10.3310/hta16190
[31] M. J. Chisti, T. Duke, C. F. Robertson, T. Ahmed, A. S. Faruque, P. K. Bardhan, S. La Vincente and M. A. Salam, "Co-Morbidity: Exploring the Clinical Overlap between Pneumonia and Diarrhoea in a Hospital in Dhaka, Bangladesh," Annals of Tropical Paediatrics, Vol. 31, No. 4, 2011, pp. 311-319. doi:10.1179/1465328111Y.0000000033

[32] M. J. Chisti, T. Ahmed, A. S. Faruque and M. Abdus Salam, "Clinical and Laboratory Features of Radiologic Pneumonia in Severely Malnourished Infants Attending an Urban Diarrhea Treatment Center in Bangladesh," Pediatric Infectious Disease Journal, Vol. 29, No. 2, 2010, pp. 174-177. doi:10.1097/INF.0b013e3181b9a4d5

[33] Y. Motarjemi, F. Kaferstein, G. Moy and F. Quevedo, "Contaminated Weaning Food: A Major Risk Factor for Diarrhoea and Associated Malnutrition," Bulletin of the World Health Organization, Vol. 71, No. 1, 1993, pp. 79-92.

[34] T. Ahmed, M. Ali, M. M. Ullah, I. A. Choudhury, M. E. Haque, M. A. Salam, G. H. Rabbani, R. M. Suskind and G. J. Fuchs, "Mortality in Severely Malnourished Children with Diarrhoea and Use of a Standardised Management Protocol," Lancet, Vol. 353, No. 9168, 1999, pp. 19191922. doi:10.1016/S0140-6736(98)07499-6

[35] T. Ahmed, B. Begum, Badiuzzaman, M. Ali and G. Fuchs, "Management of Severe Malnutrition and Diarrhea," The Indian Journal of Pediatrics, Vol. 68, No. 1, 2001, pp. 45-51. doi:10.1007/BF02728857 